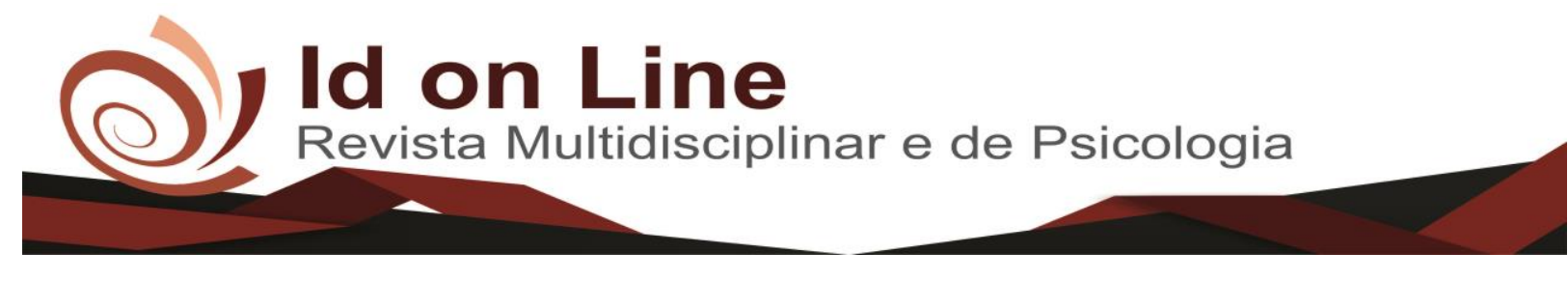

Artigo

\title{
O nível de conhecimento dos contadores sobre o código de ética da profissão.
}

\author{
João Pedro de Lima Custódio ${ }^{1}$; Viviane Correia do Prado Ferreira $^{2}$
}

\begin{abstract}
Resumo: O artigo versa sobre a temática ética na contabilidade. Muito se escreveu e certamente muito se escreverá ainda sobre o assunto "Ética", já que é um assunto que vem ganhando enorme importância no cenário atual do Brasil. Para o profissional contábil a ética é muito mais que um conceito é uma peça-chave que deve ser levada em consideração em todas as suas atividades. Seu objetivo geral averiguou o grau de entendimento dos contadores com relação ao código de ética da classe. O profissional contábil além das constantes atualizações para seguir a legislação vigente, possui também o Código de Ética que regulamenta a profissão, com objetivo de tentar reduzir a prática de atividades que profissional não deve cometer. Determinando uma direção pelo qual devem ser direcionadas suas atividades. Assim o código de ética do contador é muito mais que um guia que deve ser seguido no exercício da profissão, com direitos, limitações, punições e deveres. É na verdade um fiel norteador, que rege toda a conduta do profissional contábil. O estudo transcorreu no período de agosto a novembro de 2018, sua natureza definiu-se como básica, com objetivo exploratório e quanto ao procedimento técnico caracterizou-se como uma pesquisa exploratória. A pesquisa foi realizada com os Contadores que possuem escritório na zona urbana do município de Orós-CE, para tanto os contadores selecionados obedeceram aos seguintes critérios de inclusão: ser devidamente registrados no Conselho Regional de Contabilidade (CRC). Estar com escritório localizado na zona urbana do município de Orós - CE, na área central da cidade. Foram excluídos da pesquisa os contadores que não estão registrados no Conselho Regional, e que não tenham formação técnica na área.
\end{abstract}

Palavras Chave: Código de Ética; Contadores; Ética; Profissional.

\section{The level of knowledge of accountants on the code of ethics of the profession.}

\begin{abstract}
The article is about ethics in accounting. Much has been written and certainly much will be written on the subject "Ethics", since it is a subject that is gaining enormous importance in the current scenario of Brazil. For the accounting professional ethics is much more than a concept is a key piece that must be taken into consideration in all its activities. His general objective ascertained the degree of understanding of accountants regarding the class code of ethics. The accounting professional, besides the constant updates to follow the current legislation, also has the Code of Ethics that regulates the profession, with the purpose of trying to reduce the practice of activities that professional should not commit. Determining a direction in which their activities should be directed. Thus the code of ethics of the accountant is much more than a guide that must be followed in the exercise of the profession, with rights, limitations, punishments and duties. It is in fact a faithful guide, which governs all the conduct of the accounting professional. The study was carried out from August to November 2018, its nature was defined as basic, with an exploratory objective and the technical procedure was characterized as an exploratory research. The survey was carried out with accountants who have an office in the urban area of the municipality of Orós-CE, for which the selected accountants obeyed the following inclusion criteria: be duly registered in the Regional Accounting Council (CRC). To be with office located in the urban zone of the municipality of Orós - CE, in the central area of the city. Accountants who are not registered with the Regional Council and do not have technical training in the area were excluded from the survey.
\end{abstract}

Keywords: Code of Ethics; Accountants; Ethic; Professional.

\footnotetext{
${ }_{1}^{1}$ Aluno do curso de bacharelado em ciências contábeis da Faculdade Vale do salgado. pedrocustodio02@outlook.com ${ }^{2}$ Professor do curso de ciências contábeis da Faculdade Vale do Salgado. vivicprado@ hotmail.com

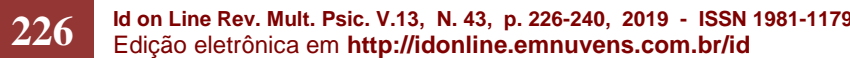




\section{Introdução}

Muito se escreveu e certamente muito se escreverá ainda sobre o assunto "Ética", já que é um assunto que vem ganhando enorme importância no cenário atual do Brasil. Para o profissional contábil a ética é muito mais que um conceito é uma peça-chave que deve ser levada em consideração em todas as suas atividades.

Para tanto existe o código de ética do contador que tem como objetivo tentar reduzir as práticas que não condizem com a postura que deve ser adotada pelo profissional. Tendo em vista que os contadores ou contabilistas vivem em um dilema ético em sua profissão, e muitas vezes são obrigados a fazer as vontades de seu cliente, mesmo que tenham que ter uma conduta não ética. Assim sendo, os contabilistas são vistos pela sociedade como "quebradores de galho" em questões fiscais e contábeis. Contribuindo para que a categoria profissional seja julgada, infelizmente, pelos maus e não pelos bons profissionais. Por este motivo deve-se manter a transparência, o contador deve divulgar as demonstrações e auditorias tem que ser realizadas, com o intuito de reduzir a desconfiança dos usuários.

Esta pesquisa é destinada para todas as pessoas interessadas no assunto, bem como é de suma importância para a classe contábil salientando a influência do código de ética no campo do exercício profissional.

Conforme o exposto, o presente estudo buscou responder a seguinte problemática: Qual o nível de sabedoria dos contadores, da cidade de Orós - CE, com relação ao código de ética da profissão? O interesse por esse estudo surgiu mediante os grandes escândalos de corrupção vividos no país, envolvendo também contadores.

Seu objetivo geral averiguou o grau de entendimento dos contadores com relação ao código de ética da classe. Os objetivos específicos da pesquisa investigaram o perfil dos contadores quanto alguns aspectos sociais e acadêmicos, Fazendo uma análise comparativa do nível de entendimento dos mesmos sobre o código de ética, averiguando se a conduta ética dos contadores é influenciada pelo código ou não.

Diante disso, este estudo tem enquanto relevância acadêmica, o intuito de definir novas estratégias para uma melhor conduta ética, baseadas no estudo realizado, que poderão ser de fato desenvolvidas, visando proporcionar o máximo de esclarecimento aos profissionais de contabilidade, contribuindo para formação de conhecimentos dos mesmos. 


\section{Fundamentação Teórica}

\section{Ética: Conceito, Origem e Evolução}

É fato que todo mundo tem um conhecimento empírico sobre a ética, adquirido no meio ou grupo social, mas quase ninguém sabe explicar o que é ética quando se é perguntado sobre a temática. Como afirmava Valls (1993), A ética é daquelas coisas que todo mundo sabe, mas que não são fáceis de explicar, quando se é perguntado.

Ao longo da história a ética sofreu diversas modificações conceituais, com vários desdobramentos, devido à existência de confusões na sua distinção com a moral, o que é bastante normal, porque um conceito não existe sem o outro, já que as palavras éticas e moral tem a mesma etimologia: a palavra grega ethos e a palavra latina morale, ambas significam hábitos e costumes.

Segundo Rosas (2002), mencionado por Carmen et al. (2008). A ética está acima da moral, para ela a moral está relacionada aos conceitos abstratos do que é certo ou errado para cada ser consciente, enquanto a ética procura resolver as dúvidas dos grupos sócias por meio da reflexão e do debate social acerca da ação concreta daquela comunidade. Assim a ética associa-se com o Direito, com as Leis, e com as práticas científicas e profissionais.

Logo, entende-se que a moral é um composto de crenças que orientam nossas ações individuais e que são decisórias em nossas escolhas e na vida em geral. A mesma se constitui através da forma como entendemos, sugamos e lidamos com o mundo ao nosso redor, os comportamentos sociais e etc. É por este motivo que a moral é algo mais individual e muito mais variável. Já a ética, se trata de um conjunto de morais universalizadas que possuem um embasamento científico.

Entretanto, é fato para alguns pensadores que ética e moral são completamente distintas, o nascimento dessa confusão está apenas na origem dos termos que é repleta de paralelos e sinônimos, mas o termo "Ética" assume diferentes significados, de acordo com o contexto em que os agentes estão envolvidos.

Uma definição de Srour (2017) define ética como um conhecimento científico que se insere no âmbito das Ciências Sociais. É um preceito teórico, um conjunto de conceitos e conhecimentos que abrangem a moralidade, que compreende as ações e decisões dos indivíduos.

Para ele a ética impacta todos os sujeitos, sejam eles ou não atuantes na execução dessas ações. Carmen et al (2008) define que a "prática e ser ético é viver logicamente com um 
pensamento ético, harmonizando o que penso daquilo que devo fazer, buscando o privilégio e a qualidade de vida de todos, da humanidade."

Valls (2017) corrobora os autores acima, quando define ética como uma aprendizagem de juízo cientifica ou filosófica que versa acerca das culturas e costumes nas mais variadas sociedades.

Já segundo Lopes de Sá (2012) a Ética, em seu significado mais amplo, pode ser entendida como a Ciência da conduta humana perante o ser e seus semelhantes. Envolvendo os estudos de aprovação ou desaprovação das ações da humanidade e a contemplação do valor como equivalente de uma avaliação do que é real e voluntarioso no campo das ações virtuosas.

A ética pode ser entendida então como o ramo da filosofia que estuda o comportamento do ser humano sob a ótica da moral enquanto norma universal que rege os comportamentos dos indivíduos sociais nas várias culturas, ao longo da história da humanidade.

\section{O Código de Ética Contábil}

O assunto "Ético" vem adquirindo enorme importância no cenário atual do mercado empresarial capitalista. A matéria vem sendo estudada com bastante ênfase nos cursos de Ciências Contábeis. Dando-se a devida importância à disciplina para que os acadêmicos se mantenham atualizados sobre o código.

De acordo com Vale e Ferreira (2016) compete ao contador o cuidado, empenho, integridade e retidão no desempenho da sua profissão, com o objetivo de cessar comportamentos inapropriados e restringir a classe contábil de quaisquer atos que venham a ferir sua reputação.

O profissional contábil além das constantes atualizações para seguir a legislação vigente, possui o Código de Ética que regulamenta a profissão, com objetivo de tentar reduzir a prática de atividades que profissional não deve cometer. Determinando uma direção pelo qual devem ser direcionadas suas atividades. De acordo com o Código de Ética Profissional do Contador, resolução $n^{\circ}$ 803/96 CFC:

Art. $1^{\circ}$ Este Código de Ética Profissional tem por objetivo fixar a forma pela qual se devem conduzir os contabilistas, quando no exercício profissional e nos assuntos relacionados à profissão e à classe.

O código de ética do contador é muito mais que um guia que deve ser seguido no exercício da profissão, com direitos, limitações, punições e deveres. É na verdade um fiel 
norteador, que rege toda a conduta do profissional contábil. O artigo segundo e seus incisos estabelecem como deve ser sua conduta:

[...] I - exercer a profissão com zelo, diligência, honestidade e capacidade técnica, observada toda a legislação vigente, em especial aos Princípios de Contabilidade e as Normas Brasileiras de Contabilidade, e resguardados os interesses de seus clientes e/ou empregadores, sem prejuízo da dignidade e independência profissionais;

II - guardar sigilo sobre o que souber em razão do exercício profissional lícito [...]

(CONSELHO FEDERAL DE CONTABILIDADE, 2010)

Uma conduta não ética de um contador ou contabilista, no exercício de sua profissão, pode agradar a quem se beneficia diretamente dessa conduta. Porém este ato apenas contribui para denigrir a credibilidade e a confiabilidade não só de quem a praticou, como também de toda a comunidade contábil. Assim o código de ética do profissional contábil (CEPC) determina penalidades para o descumprimento da norma cometido pelo profissional:

Art. 12 A transgressão de preceito deste Código constitui infração ética, sancionada, segundo a gravidade, com a aplicação de uma das seguintes penalidades:

I - advertência reservada;

II - censura reservada;

III - censura pública.

Os diversos escândalos envolvendo empresas nacionais e internacionais de contabilidade intensificam a preocupação da sociedade quanto à fidelidade e confiabilidade das informações das empresas. Por isso as questões éticas são bastante discutidas hoje no campo organizacional, governamental e profissional.

Para Santos et al. (2016) toda profissão deve ser respaldada por um código de ética, uma vez que sem o mesmo não há como se estruturar um trabalho de forma equânime. Pois, é pela execução dos valores morais que o profissional edifica sua carreira, ofertando-lhes dignidade e extinguindo a corrupção, dessa forma, é dever do contador seguir fielmente os preceitos éticos.

\section{A Conduta Ética do Profissional.}

O Contador não pode perder seus valores éticos, é o que afirma Sousa, Santos e Silva (2015), para os mesmos a ética deve ser um atributo do profissional contábil, uma vez que estes especialistas perpassam a atividade humana frente aos patrimônios e impulsionam a economia. 
Os autores supracitados afirmam ainda, que durante esse ciclo econômico a contabilidade diagnostica os clientes com relação às posses, fomentando informações e correções nos processos de planejamento.

O profissional contábil deve ter um comportamento ético inquestionável, principalmente nos dias atuais devidos aos grandes escândalos envolvendo contadores, por isso o contador deve saber manter sigilo, ter competência para proporcionar aos usuários informações fidedignas com segurança e confiabilidade e, ao mesmo tempo, ter uma conduta pessoal digna de forma a não se sentir seduzido em fraudar informações.

Segundo Lopes de Sá (2012) existem muitas virtudes que o profissional deve ter para progredir com eficácia seu trabalho. Para ele a honestidade é a virtude magma no campo profissional, "É necessário ser honesto, parecer honesto e ter o ânimo de sê-lo, para que exista a prática do respeito ao direito de nosso semelhante".

Segundo Feil, Diehl e Schuck (2017), o profissional contábil não deve se autopromover, pois se assim o fizer, desencadeara problemas no sistema econômico como um todo além de "manchar" sua integridade e reputação para com os empregadores desencadeando auditorias e investigações acerca da atuação do mesmo.

Diante disto, verifica-se que o contador ou contabilista vive em um dilema ético em sua profissão, pois em seu cotidiano ele deve fazer escolhas a todo tempo, e seu cliente nem sempre quer agir de forma ética.

Assim para o profissional contábil a ética é mais que um conceito, que deve ser seguido à risca, é uma peça indispensável que deve ser acatada em todas as suas atividades, pois para o exercício da profissão, não basta apenas à preparação técnica, é inevitável que o contador defenda os princípios e valores éticos cabíveis a sua profissão, de modo a produzir uma imagem verdadeira e diferente do que ela se constitui para as novas gerações de profissionais.

\section{Metodologia}

A pesquisa foi realizada na cidade de Orós - CE, situada no leito do rio Jaguaribe, na região centro-sul do Ceará, distante 340,8 Km da capital Fortaleza. Segundo Instituto Brasileiro de Geografia e Estatística - IBGE (2016) sua população é estimada em 21.389 habitantes e possui uma área de $576,270 \mathrm{~km} 2$. 
O estudo transcorreu no período de agosto a novembro de 2018, sua natureza definiu-se como básica, com objetivo exploratório e quanto ao procedimento técnico caracterizou-se como uma pesquisa exploratória.

Quanto à abordagem do problema, sucedeu-se ao hipotético-dedutivo e a pesquisa adotada no estudo foi do tipo quantitativo, pois o mesmo utiliza diferentes técnicas estatísticas para quantificar, para um determinado estudo, opiniões e informações. É realizado para compreender e enfatizar o raciocínio lógico e todos os dados que se possam mensurar sobre as experiências humanas.

A população estudada foram todos os contadores situados na zona urbana do município de Orós - CE, com escritório de contabilidade situado na área central da cidade. Para tanto os contadores selecionadas obedeceram aos seguintes critérios de inclusão: ser devidamente registrados no Conselho Regional de Contabilidade (CRC) ou com formação técnica na área. Estar com escritório localizado no centro da zona urbana do município de Orós - CE. Já os critérios de exclusão foram: os contadores que não estão registrados no Conselho Regional, e que não tenham formação técnica na área.

O instrumento para coleta dos dados da pesquisa referiu-se a um questionário elaborado com questões fechadas. A pesquisa transcorreu no mês de agosto a dezembro de 2018 e os dados coletados foram devidamente analisados por meio de distribuição de frequência, através do programa Microsoft Excel 2010.

Desse modo o objeto desse estudo acatou ao disposto na resolução ${ }^{\circ} 510$, de 07 de abril de 2016 do Conselho Nacional de Saúde, visando proteger os entrevistados, além deste, contribuir na aplicação do estudo conforme os parâmetros éticos.

\section{Análise e discursão dos resultados}

Em consonância com o trajeto metodológico supracitado e com o instrumento de coleta de dados desse estudo, encontrou-se uma amostra de cinco (5) entrevistados. Estes, foram perguntados sobre as caracterizações sociodemográficas nas variáveis: sexo, faixa de idade e último curso concluído na área.

Dessa forma, obteve-se o predomínio do sexo masculino em 3 entrevistados (60\%), seguido pelo sexo feminino em 2 profissionais (40\%). As faixas etárias de idade dominantes foram de 35 a 45 anos e acima de 60 anos, ambas com 2 contadores cada (40\%), sucedida pelos profissionais de 45 a 60 anos em 1 entrevistado (20\%). A última formação acadêmica dos 
contadores foi o bacharelado em 3 entrevistados (60\%), seguido pelos especialistas e técnicos, ambos com 1 profissional cada (20\%). Vide Tabela 1.

Tabela 1 - Perfil Sociodemográfico dos Entrevistados

\begin{tabular}{ccc}
\hline Variável & N & \% \\
\hline Sexo & 2 & $40 \%$ \\
Feminino & 3 & $60 \%$ \\
Masculino & & \\
Idade & 2 & $40 \%$ \\
35 a 45 anos & 1 & $20 \%$ \\
45 a 60 anos & 2 & $40 \%$ \\
Acima de 60 anos & & \\
Última Formação & 1 & $60 \%$ \\
Técnico & 3 & $20 \%$ \\
Bacharelado & 1 &
\end{tabular}

Fonte: Dados da Pesquisa, Orós - CE, 2018.

Estes dados estão em consonância com o estudo de Anjos et al. (2011), sobre o Código de Ética e as ações éticas na vida pessoal realizado com profissionais de contabilidade. Este destacou a prevalência do sexo masculino em $56 \%$ da sua amostra, afirmando que o gênero pouco influi na prática contabilística.

Com relação às faixas etárias, a pesquisa de Morais, Silva e Carvalho (2010), sobre o comportamento dos contabilistas diante de diferentes dilemas éticos assemelha-se aos achados desse estudo, destacando a predominância de profissionais com idades entre 20 e 55 anos, com uma média de 28,20 anos. Tais resultados inferem que profissionais mais velhos tendem a praticar atitudes mais éticas do que os mais novos.

Quanto a variável da última formação acadêmica, o estudo de Alves et al. (2007), sobre a importância do código de ética profissional para o contabilista está em similaridade com achados desse estudo, apresentado uma amostra de 68,3\% de contadores graduados, 30,85\% técnicos de contabilidade e 7\% sendo profissionais de outras áreas

Com relação aos dados sobre o conhecimento dos profissionais contadores sobre o Código de Ética, nesse estudo as respostas foram empregadas de acordo com afirmativas elaboradas de 1 a 10, nas quais os entrevistados deveriam marcar de 1 a 5 conforme o nível de concordância, sendo o valor máximo a assertiva "Concordo Totalmente". Após essa etapa, as respostas foram tabuladas e analisadas de acordo com as frequências em porcentagens e destacadas na Tabela 2. 
Tabela 2 - Descrição das alternativas questionadas aos profissionais de contabilidade.

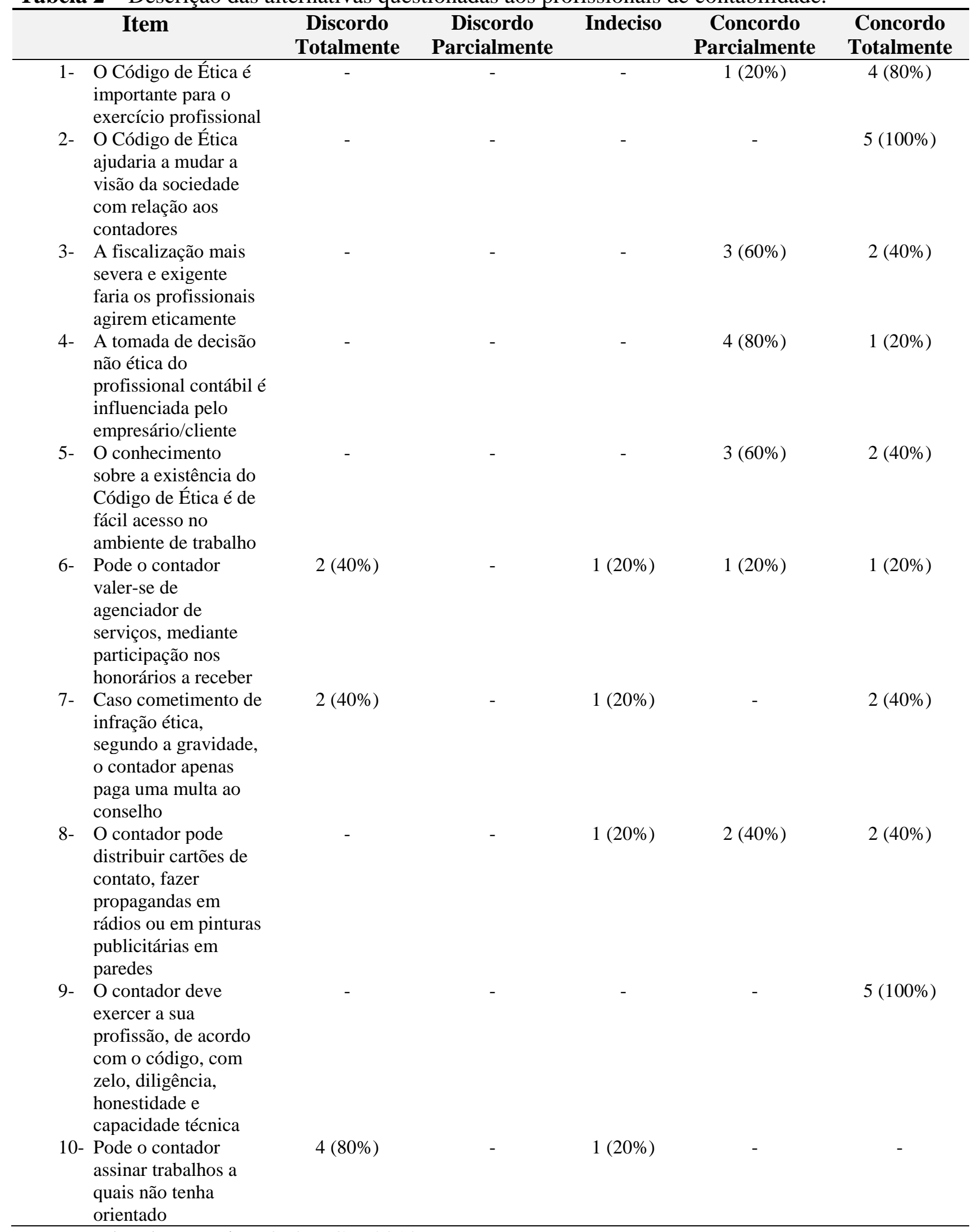

Fonte: Dados da Pesquisa, Orós - CE, 2018. 
Dessa forma, os dados desse estudo evidenciam que o Código de Ética é importante para $80 \%$ (4) dos entrevistados, sendo que $100 \%$ (5) atribuem importância na melhoria da visão social quando se utilizam desse documento.

Oliveira e Souza (2013) reafirmam tais dados destacando que a contabilidade como uma ciência social que deve incorporar medidas justas e viáveis, sempre a fim de elevar os serviços prestados aos clientes, exercendo seu papel com consciência e de acordo com o elencado no Código de Ética para melhorar a sua imagem social.

Desse modo, as respostas encontradas nesse estudo sobre a fiscalização severa e exigente na prática ética, 60\% (3) dos profissionais concordaram parcialmente com essa afirmativa e $40 \%$ (2) concordaram totalmente com a relevância da vigilância para a melhoria ética na profissão contábil.

Tais dados estão em similaridade com a pesquisa de Almeida e Alves (2014), sobre as análises de comportamentos éticos dos contadores em ambientes internacionais de trabalho, salientando que $57 \%$ dos profissionais entrevistados concordaram totalmente que as suas condutas são mais qualitativas quando passam por supervisão.

O estudo de Monteiro e Chacon (2005), que reforça a importância dos órgãos fiscalizadores e reguladores para a melhoria da Contabilidade, principalmente os Conselhos de Contabilidade que atuam em consonância com o Código Deontológico, pois somente uma prática respaldada sob os saberes éticos conseguirá reconhecimento.

Dessa maneira, a tomada de decisão não ética do profissional contábil é influenciada pelo empresário/cliente obteve $80 \%$ (4) das respostas com concordância parcial e 20\% (1) com concordâncias totais nesse estudo. Em virtude desses dados, o estudo de Berlatto et al. (2015), sobre as contribuições da ética para a contabilidade afirma que o contabilista deve ter condutas éticas, para manter sua reputação e não lesar os seus clientes, pois no atual cenário de corrupção o cliente pode levar o profissional a praticar ações não condizentes com a ética e a moral, assim a ciência contábil deve manter firmemente os seus princípios de acordo com o seu código.

Com relação à afirmativa do conhecimento sobre a existência do Código de Ética ser de fácil acesso no ambiente de trabalho, obteve-se nesse estudo uma 60\% (3) de concordância parcial e $40 \%$ (2) de concordância total a esta alegação.

O estudo de Noronha, Santana e Nunes (2009), sobre a percepção da classe contadora nos serviços prestados na capital de Brasília, no Distrito Federal, demostrou que 51\% da sua amostra concordam que a implantação de normas do Código de Ética nos trabalhos é eficaz para a qualidade e eficiência das suas práticas. 
No que concerne aos dados sobre a valência do contador como agenciador de serviços, mediante participação nos honorários a receber encontrados nesse estudo, identificou-se que $40 \%$ (2) dos profissionais discordam totalmente e, respectivamente, $20 \%$ concordam parcialmente, totalmente ou foram indecisos em suas respostas.

Segundo o Conselho Federal de Contabilidade (CFC, 2003), o contador pode agenciar seus serviços de acordo com propostas financeiras especificas, bem como receber honorários condizentes com o prazo, duração e condições do serviço prestado, respaldando assim, os achados desse estudo.

Quanto a variável do acometimento de casos de infração ética, segundo a gravidade, onde o contador apenas paga uma multa ao conselho, respectivamente $40 \%$ (2) da amostra discordam totalmente dessa afirmativa e concordam totalmente, sendo que $20 \%$ (1) esteve indeciso.

O estudo sobre a aplicação de penalidades aos profissionais contabilistas de Silva e Rodrigues (2008), demostrou que quando os profissionais realizam infrações éticas, estes devem receber, segundo as bases legais na Resolução CFC 803/96 c/c e na Resolução CFC 960/03, as seguintes penalidades: Advertência Reservada Censura Reservada, Censura Pública. Sendo que dentre a amostra analisada em seu estudo, $12 \%$ apresentaram condenações, $51,11 \%$ apresentaram infrações disciplinares.

No que tange a distribuição de cartões de contato, propagandas em rádios ou em pinturas publicitárias em paredes encontradas nas respostas desse estudo, mutuamente $40 \%$ (2) dos entrevistados concordaram parcialmente e totalmente com essa afirmativa, sendo que $20 \%$ (1) foram indecisos.

A pesquisa de Peleias et al. (2007), afirma que o uso de propagandas e estratégias de marketing são fundamentais para divulgar a contabilidade e os serviços de forma ética, pois essas ferramentas ressaltam a relevância operacional e estratégica das organizações, incentivando a comunicação, transmitindo as informações e o posicionamento dos profissionais frente ao mercado de trabalho.

No que se refere ao contador exercer a sua profissão, de acordo com o código, com zelo, diligência, honestidade e capacidade técnica, encontrou-se nesse estudo que $100 \%$ (5) dos profissionais concordam totalmente com essa prerrogativa. Assim sendo, quanto a assinatura dos contadores em trabalhos com os quais não tenham orientado, obteve-se nesse estudo uma prevalência de $80 \%$ (4) em discordância total e $20 \%$ (1) com indecisão nesta afirmativa.

O estudo de Martins e Bencke (2018), sobre a postura ética na contabilidade contrapõe os achados acima, afirmando em seu estudo que $35 \%$ dos estudantes ou profissionais de 
contabilidade não aplicam os preceitos da moral e ética na tomada de decisão das suas práticas cotidianas, o que influencia diretamente no profissional.

Logo, a ética tem um papel primordial para a contabilidade, pois fomenta regulamentações, princípios, limitações e práticas que facilitam o exercício contábil, desenvolvem a consciência coletiva na profissão e conduzem os profissionais para uma convivência harmoniosa (BERNI; BOLOGNESI, 2018).

\section{Considerações finais}

A aplicação do trabalho possibilitou conhecer e identificar de fato o grau de conhecimento dos contadores, haja vista que o código de ética da profissão ministra informações de extrema relevância, sendo de suma importância para angariar a confiabilidade e integridade do profissional contábil. Nesta acepção, cabe destacar que o contador como preposto de seu cliente, é considerado responsável solidário, sendo assim, em grosso modo, é consciente pelos atos e fatos junto ao preponente. Portanto, são situações que além de ferir sua imagem, também podem responsabilizar aqueles que contribuíram para difusão de informações não fidedignas, mesmos que estes tenham sido requisitados pelos clientes.

Como principais resultantes da pesquisa, observou-se que a grande maioria dos profissionais optou por atender as normas e princípios éticos estabelecidos no código de ética. No entanto, ainda que em uma porcentagem menor, foram constatadas taxas significativas de profissionais que não acatam a algumas normas e princípios presentes no instrumento de coleta de dados. Conquanto o estudo tenha uma mostra limitada, que por sua vez não outorga que sejam generalizados os resultados encontrados, compreende-se que são evidencias suficientes para constatar que uma parcela dos profissionais contábeis desatendem as normas de conduta da profissão contábil e fazem de tudo para prover o cliente satisfeito, mesmo que, para isso tenha que servir-se de práticas inadequadas.

Todavia é necessário que se tenha o máximo de orientação das instituições de ensino superior a respeito das boas práticas contábeis, bem como uma fiscalização mais rigorosa do exercício da profissão contábil a fim de possibilitar maior valorização do contador na atual sociedade. É necessário também, devido a sua carência, que haja um número maior de pesquisas e campanhas que retratam essa realidade, pois para manter uma boa imagem desse profissional é fundamental que se mantenham atualizados e conscientizados sobre o tema. 


\section{Referências}

ALMEIDA, Sidmar Roberto Vieira; ALVES, Francisco José dos Santos. Análise do comportamento ético dos profissionais de Contabilidade no ambiente de convergência às Normas Internacionais de Contabilidade. Revista Uniabeu, v. 7, n. 15, p. 320-335, 2014. Disponível em: <http://revista.uniabeu.edu.br/index.php/RU/article/view/1234/pdf_90>. Acesso em: 14 nov. 2018.

ALVES, Francisco José dos Santos. et al. Um estudo empírico sobre a importância do código de ética profissional para o contabilista. Revista Contabilidade \& Finanças, v. 18, n. spe, p. 58-68, 2007. Disponível em: 〈http://www.periodicos.usp.br/rcf/article/view/34224/36956 >. Acesso em: 14 nov. 2018.

ANJOS, Luiz Carlos Marques dos. et al. Código de Ética e o Comportamento ético na vida pessoal: um estudo junto a pessoas envolvidas com a Contabilidade. Revista de Contabilidade da UFBA, v. 5, n. 2, p. 4-19, 2011. Disponível em: <https://rigs.ufba.br/index.php/rcontabilidade/article/view/5482/3966>. Acesso em: 14 nov. 2018.

BERLATTO, Odir. et al. As Contribuições da Ética ao Profissional da Contabilidade. Revista de Gestão e Contabilidade da UFPI, v. 2, n. 1, 2015. Disponível em: $<$ http://www.atena.org.br/revista/ojs-

2.2.308/index.php/GECONT/article/viewFile/2514/2148>. Acesso em: 14 nov. 2018.

BERNI, Daniele Cristina Vieira; BOLOGNESI, Roselaine. A ética na profissão contábil: uma pesquisa documental. UNIVERSITAS, n. 22, 2018. Disponível em: < http://www.revistauniversitas.inf.br/index.php/UNIVERSITAS/article/download/323/213>.

Acesso em: 17 nov. 2018.

BUENO, C. M.; PEREZ M. CA. Práticas em educação especial e inclusiva. Ministério da educação, 2008.2 P.10- Disponível em: <http://www2.fc.unesp.br/educacaoespecial/material/Livro4.pdf $>$ Acesso em: 18 de agosto de 2018.

CFC. Conselho Federal de Contabilidade. Contrato de Prestação de Serviços de Contabilidade. Brasília, DF. CFC, 2003, 54.p. Disponível em: <http://crcmg.org.br/media/avulsos/servicos/contrato.pdf>. Acesso em: 15 nov. 2018.

CÓFIGO DE ÉTICA DO PROFISSIONAL CONTÁBIL. Resolução CFC nº83/96. Disponível em:< http://www.portaldecontabilidade.com.br/nbc/res803.htm> Acesso em: $18 \mathrm{de}$ agosto de 2018.

DADOS GERAIS DO MUNICÍPIO. Brasil, Ceará. 2016. IBGE. Disponível em:< https://cidades.ibge.gov.br/painel/painel.php?lang=\&codmun=230950\&search=||infogr\%E1fi cos:-dados-gerais-do-munic\%EDpio> Acesso em: 18 de setembro de 2018.

FEIL, A. A.; DIEHL, L.; SCHUCK, R. J. Ética profissional e estudantes de contabilidade: análise das variáveis intervenientes. Cadernos EBAPE. BR, v. 15, n. 2, p. 256-273, 2017. 
MARTINS, Patricia Jung; BENCKE, Fernando Fantoni. Ética geral e profissional em contabilidade: um estudo sobre a postura de discentes e profissionais em contabilidade. Revista de Contabilidade da UFBA, v. 12, n. 2, p. 150-165, 2018. Disponível em: $<$ https://portalseer.ufba.br/index.php/rcontabilidade/article/download/23502/16072>. Acesso em: 17 nov. 2018.

MONTEIRO, Teresa Murcia Leite; CHACON, Márcia Josienne Monteiro. Um caso de ética profissional: a relação das empresas com o Conselho de Contabilidade. In: Seminário Acadêmico de Contabilidade (SEACON), v. 10, 2005, 24.p. Disponível em: $<$ https://s3.amazonaws.com/academia.edu.documents/33738630/Artigo_Etica_Seacon.pdf?A WSAccessKeyId=AKIAIWOWYYGZ2Y53UL3A\&Expires $=1542562698 \&$ Signature $=232$ Y 2 tMFbiXT852zXHSq\%2FOKznt0\%3D\&response-content-

disposition=inline\%3B\%20filename\%3DArtigo_Etica_Seacon.pdf $>$. Acesso em: 14 nov. 2018.

MORAES, Melissa Christina Corrêa de; SILVA, Aline Moura Costa da; CARVALHO, Frederico Antônio Azevedo de. O comportamento dos futuros contabilistas perante diferentes dilemas éticos. Pensar contábil, v. 12, n. 48, 2010. Disponível em: $<$ http://www.atena.org.br/revista/ojs-2.2.3-

08/index.php/pensarcontabil/article/viewFile/776/765>. Acesso: 14 nov. 2018.

NORONHA, Pedro Luiz Rocha de; SANTANA, Claudio Moreira; NUNES, Danielle Montenegro Salamone. Percepção de classe: Estudo com profissionais contadores no Distrito Federal. v. 1, 17.p., 2009. Disponível em: $<$ https://www.researchgate.net/profile/Claudio_Santana/publication/238078956_PERCEPCA O_DE_CLASSE_ESTUDO_COM_PROFISSIONAIS_CONTADORES_NO_DISTRITO_FE DERAL/links/54063fd50cf2c48563b24bed/PERCEPCAO-DE-CLASSE-ESTUDO-COMPROFISSIONAIS-CONTADORES-NO-DISTRITO-FEDERAL.pdf $>$. Acesso em: 14 nov. 2018.

OLIVEIRA, Jones Santos; SOUZA, Roberto Francisco de. Contabilidade criativa e a ética profissional. Revista Científica da Ajes, v. 4, n. 8, 2013. Disponível em: <http://www.revista.ajes.edu.br/index.php/rca/article/view/23/12>. Acesso em: 14 nov. 2018.

PELEIAS, Ivam Ricardo. et al. Marketing Contábil: pesquisa com escritórios de contabilidade no Estado de São Paulo. Revista Contabilidade, Gestão e Governança, v. 10, n. 1, 2009. Disponível em: $<$ https://www.cggamg.unb.br/index.php/contabil/article/download/149/pdf_103>. Acesso em: 16 nov. 2018.

SÁ, ANTÔNIO LOPES DE. Ética profissional. 9ed. São Paulo: Atlas S/A, 2012. 254p. p 3,p.205.

SANTOS, T. L. et al. A Percepção dos Profissionais da Contabilidade à Luz dos Princípios Éticos e Norma Brasileira de Contabilidade (NBC PG 100) no Município de Tomé-Açu-Pará. Revista Paraense de Contabilidade, v. 1, n. 1, p. 34-43, 2016.

SILVA, Ricardo Cabral da; RODRIGUES, Adriano. Aplicação de penalidades aos contabilistas do estado do espírito santo. In: $\mathbf{2}^{\mathbf{0}}$ Congresso UFSC de Controladoria e Finanças, v. 1, 13.p., 
2008. Disponível em: 〈http://dvl.ccn.ufsc.br/congresso/anais/2CCF/20080718161309.pdf〉. Acesso em: 16 nov. 2018.

SOUSA, C. P.; SANTOS, C. M; SILVA, L. B. V. A Moralidade pública e a Contabilidade: O papel social desse profissional fundamentado na responsabilidade ética, civil e penal/public morality and accounting: the social role of the reasoned professional ethics, civil and criminal liability. Revista Jurídica Eletrônica da UFPI, v. 2, n. 01, p.130, 2015.

SROUR, R. Ética empresarial. Editora: Elsevier Brasil, 5a edição, p.418, 2017. Disponível em:< https://books.google.com.br/books?hl=pt-

BR\&lr=\&id=lzk8DwAAQBAJ\&oi=fnd\&pg=PT7\&dq=DEFINI\%C3\%87\%C3\%83O+DE $\%$ C3\%89TICA\&ots=eySb2jPVq-

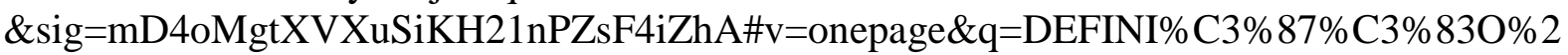
0DE\%20\%C3\%89TICA\&f=false >. Acesso em: 20 de setembro de 2018.

VALE, L. R.; FERREIRA, F. M.; WIESNER, R. A aplicação prática do código de ética na prestação de serviços contábeis. Revista Brasileira de Contabilidade, n. 221, p. 16-29, 2016.

VALLS, A.LM. O que é ética. Editora: Brasiliense, 2017. Disponível em:< https://books.google.com.br/books?hl=pt-

BR\&lr=\&id=ZGAvDwAAQBAJ\&oi=fnd\&pg=PT4\&dq=DEFINI\%C3\%87\%C3\%830+DE+ $\% \mathrm{C} 3 \%$ 89TICA\&ots=agNrwOAYD0\&sig=8bc2JKdgFjQ9Ryd9DN1sYpVLJVE\#v=onepage $\& \mathrm{q}=\mathrm{DEFINI} \% \mathrm{C} 3 \% 87 \% \mathrm{C} 3 \% 83 \mathrm{O} \% 20 \mathrm{DE} \% 20 \% \mathrm{C} 3 \% 89 \mathrm{TICA} \& \mathrm{f}=$ false $>$. Acesso em: $20 \mathrm{de}$ setembro de 2018.

VALLS, Álvaro L.M. O que é ética. 7a edição Ed. Brasiliense, 1993.

\section{Como citar este artigo (Formato ABNT):}

CUSTÓDIO, João Pedro de Lima; FERREIRA, Viviane Correia do Prado. O nível de conhecimento dos contadores sobre o código de ética da profissão. Id on Line Rev.Mult. Psic., 2019, vol.13, n.43, p. 226-240. ISSN: 1981-1179.

Recebido: 23/11/2018;

Aceito: $24 / 11 / 2018$ 